Article

\title{
Assessing the Environmental Potential of Collaborative Consumption: Peer-to-Peer Product Sharing in Hammarby Sjöstad, Sweden
}

\author{
Michael Martin $1, * \mathbb{D}$, David Lazarevic ${ }^{2}$ and Charlie Gullström ${ }^{3}$ \\ 1 LCA and Environmental Management, IVL Swedish Environmental Research Institute, Valhallavägen 81, \\ 11428 Stockholm, Sweden \\ 2 Environmental Policy Centre, Finnish Environment Institute SYKE, PL 140, 00251 Helsinki, Finland; \\ David.Lazarevic@ymparisto.fi \\ 3 Department of Architecture, KTH-Royal Institute of Technology, Osquars backe 9, 11428 Stockholm, \\ Sweden; charlie.gullstrom@arch.kth.se \\ * Correspondence: michael.martin@ivl.se; Tel.: +46-10-788-66-81
}

Received: 5 November 2018; Accepted: 21 December 2018; Published: 2 January 2019

\begin{abstract}
Collaborative consumption-through sharing services—has been promoted as an important step in transforming current consumption patterns toward more sustainable practices. Whilst there are high expectations for sharing services, there are few studies on the potential environmental benefits and impacts of sharing services. This study aims to analyze the potential environmental impacts of a peer-to-peer ( $\mathrm{P} 2 \mathrm{P})$ product sharing platform and potential integration with a package drop-off/pick-up service in the urban district of Hammarby Sjöstad, Stockholm, Sweden. A life cycle approach is adopted, taking into account product lifetime and use, the potential replacement of conventional products and services, impacts from digital infrastructure and their impacts on the environment. The results indicate that there is significant potential for these sharing services to reduce environmental impacts associated with production and consumption; primarily through avoiding production and reducing the production impacts of new product purchases. The results also illustrate potential synergies to integrate with the package drop-off/pick up service; where the impacts from shared products are further reduced by reducing transportation impacts through improved logistics. However, the results are dependent upon, and sensitive to, a number of methodological choices and assumptions; highlighting the need for greater knowledge on the use environmental assessments of sharing services.
\end{abstract}

Keywords: collaborative consumption; sharing economy; life cycle assessment (LCA); peer-to-peer (P2P), sharing platform; environmental impacts; sustainability

\section{Introduction}

The sharing economy-also referred to as collaborative consumption-is a broad umbrella construct $[1,2]$ that represents different forms of coordinated "sharing, bartering, lending, trading, renting, gifting, and swapping" [3] (p. xv). Normative expectations for the sharing economy range from its role in a post-capitalist zero marginal cost society that will overthrow capitalism [4], to a nightmarish form of neoliberal capitalism [5].

The sharing economy is often framed as a more sustainable form of consumption [5]; presenting "a new pathway to sustainability" [6] (p. 228). In this framing, the environmental and social impacts from the unsustainable consumption of goods and services [7] are addressed through a "new and sustainable form of consumption based on individuals accessing rather owning resources" [5] (p. 154). Indeed, Böcker and Meelen [8] reveal that environmental reasons rank as the greatest motivation for 
people to engage in car and ride-sharing and it is the primary motivation for women to engage in collaborative consumption.

There is an intuitive environmental logic of the sharing economy. The production of goods is energy and material intensive and the source of significant environmental damage. By sharing goods-based on either reciprocity or market transitions-the environmental impacts of primary production are avoided, scare resources are preserved and residual waste to landfill is minimized. However, given the increasing amount of literature on business models for the sharing economy [9], there are a limited number of studies that compare the environmental impacts of the sharing economy to conventional modes of consumption.

The environmental impacts of the collaborative consumption are complex. Studies have investigated the environmental dimension of the sharing economy in the areas of transportation (e.g., $[10,11])$, clothing (e.g., [12,13]), housing/accommodation (e.g., [14,15]), within households (e.g., [16,17]) and consumer goods (e.g., $[18,19])$. However, the potential drawbacks of the sharing economy have also been highlighted. For instance, Clewlow and Mishra [20] have shown that the introduction of ride-sharing can increase congestion and divert commuters from public transport systems, and Briceno et al. [21] have demonstrated that if rebound expenditure from car-sharing was spent on air travel, car-sharing would have higher overall emissions than conventional car-ownership. In the industrial ecology field, analogous approaches, such as product-service systems have also been reviewed. For example, Agrawal et al. [22] have found that leasing products are not necessarily more environmentally friendly than purchasing. Furthermore, rebound effects that negate the positive benefits of sharing from have been highlighted $[12,17,23]$.

In recent years, product sharing via peer-to-peer (P2P) platforms is becoming increasingly available, through a number of initiatives, e.g., sharing services, boards, physical events, etc.; often promoted as an approach to improve sustainability of consumptive patterns in urban areas [24]. Hence, whilst the sharing economy is promoted as a more environmentally friendly option, it is becoming ever more important to understand the environmental implications of collaborative consumption. However, there is a lack of detailed studies that consider the environmental impacts of P2P platform-coordinated product sharing. In order to review the environmental implications of the sharing economy, environmental systems analysis tools may be required to capture the potential benefits and trade-offs of P2P platforms from a life cycle perspective. Life cycle assessment (LCA) can be utilized to assess the potential environmental impacts and resource use of a product/service throughout out its life cycle; i.e. from raw material extraction, via production and use phases, to waste management and transportation along the way [25]. Again, however, P2P sharing between users is complex, and few assessments have been made outside of mobility, housing and clothing sectors, with no methodological guidelines available in the literature for guiding the assessments; and a limited set of studies to compare with.

The aim of this study is to outline methodological considerations for reviewing the environmental performance of P2P services and to apply these methodological considerations to review a P2P service in the urban district, Hammarby Sjöstad, of Stockholm to assess its potential. The sharing service includes a P2P online platform and a supporting service for goods delivery and collection. The target audience of the article is the scientific community and practitioners who seek methodological guidance for understanding the environmental impacts of sharing services.

\section{Methodology}

The following sections outline the methodology employed in this article, the description of the LCA goal and scope, and the studied P2P sharing platform and scenarios reviewed.

\subsection{Methodology for Reviewing Environmental Impacts of Sharing Services}

The potential environmental impacts associated with sharing services can occur at different phases of a product's life cycle; from the extraction of raw materials to the use of the product and final disposal. 
Figure 1 depicts the different life cycle phases for a shared product using a sharing platform or service. Impacts for the products include the raw materials and production impacts. Thereafter, the product is made available directly, or through retail operations, to the owner or user. Throughout this process, there are energy and transportation impacts. Unlike linear consumption patterns, the sharing of products alters the use phase of the product by allowing the product to be available to be used by multiple users. The ownership phase can include, e.g., so-called "libraries" or private consumers sharing goods (hereafter referred to as providers) and includes e.g. the infrastructure and logistics for the sharing platform to be functional. In Figure 1, this is depicted as the "loop" between the use and ownership phases. In the assessment below, the end-of-life phase is not considered, as the products are assumed to be in use after the period of assessment, i.e., one year.

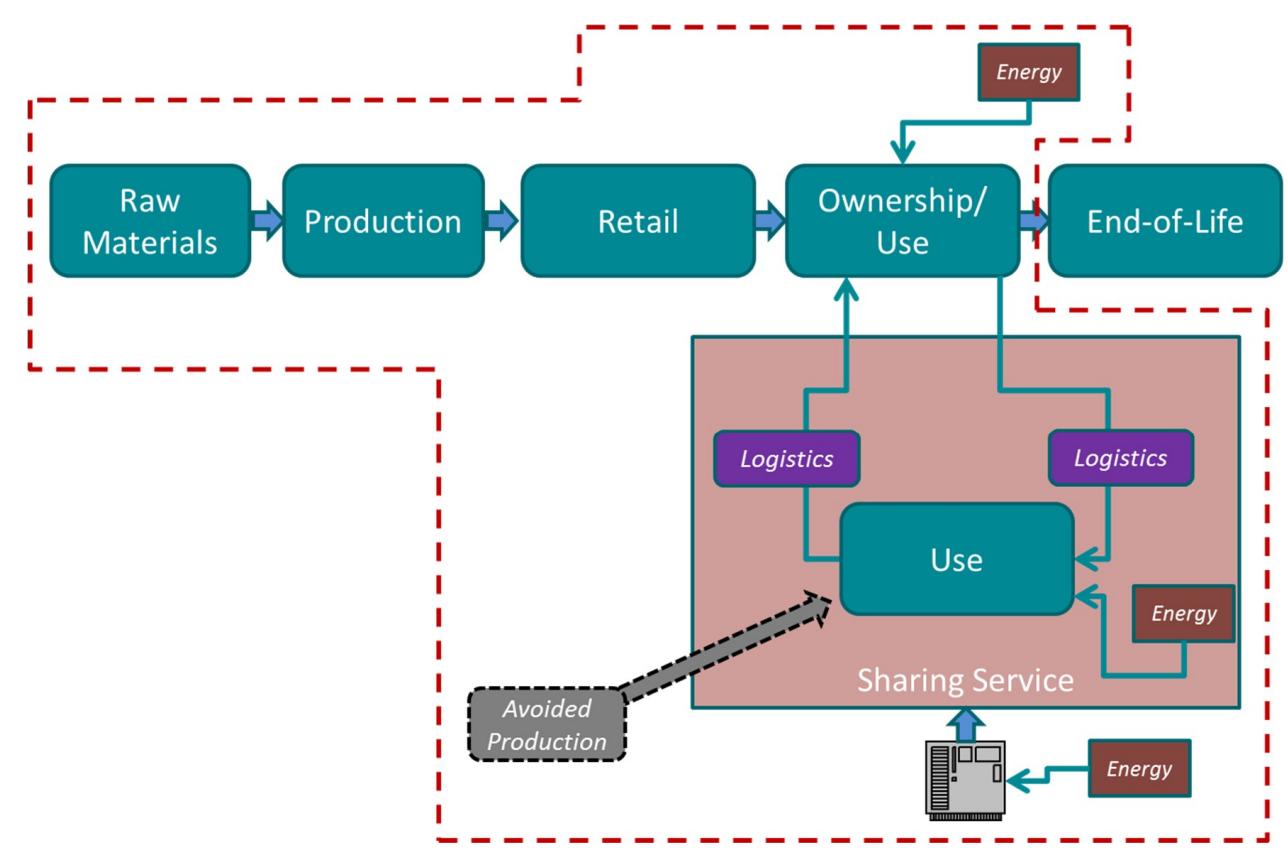

Figure 1. Life cycle phases associated with a product being shared through a sharing service.

The dashed line represents the system boundaries of the assessment.

The life cycle impacts from sharing services can be outlined using Equation 1 below, which outlines the overall impact of the sharing service $\left(I_{S}\right)$, including the impacts from the product's production $\left(I_{P}\right)$, retail $\left(I_{R}\right)$, shipping and logistics $\left(I_{L}\right)$, use $\left(I_{U}\right)$, sharing infrastructure $\left(I_{S I}\right)$ and credits for potential replacement of products $\left(I_{R P}\right)$ due to avoided product purchases.

$$
I_{S}=I_{P}+I_{R}+I_{U}+I_{L}+I_{S I}+I_{R P}
$$

The environmental impacts associated with a shared product $\left(I_{P}\right)$ include the environmental impacts for the raw materials, production process and all associated energy and transportation needed to produce the final product available for retail. Retail impacts $\left(I_{R}\right)$ can include all energy, services, and transportation of the products until the point of sale. The impacts from the use of the product $\left(I_{U}\right)$ vary between the different products and sharing services assessed; which can include inputs of, e.g., energy and other materials. Impacts from the logistics $\left(I_{L}\right)$ include the transportation of the product from the provider to the user and back again, accounting for the transportation distance and mode. Impacts from the sharing infrastructure $\left(I_{S I}\right)$ include e.g., the impacts from the digital sharing platform (webpage, data traffic, use of mobile phone or computer to search and rent/lend the product(s) and data storage) or any traditional infrastructure needed for sharing (e.g., small garages and locking mechanisms). Finally, as sharing a product has the potential to replace the purchase of conventional products, impacts from the replaced products $\left(I_{R P}\right)$ may also be included where relevant. 
For this study, the preceding life cycle approach was adopted to assess the environmental impacts of sharing services compared to the conventional consumption of products. The goal of the environmental assessment is to assess the impacts from sharing platforms, potential improvements and important methodological considerations for reviewing sharing services and platforms. The functional unit of the assessment is the annual sharing of products through the P2P product sharing platform within the Hammarby Sjöstad urban area; see further information below.

In the assessment which follows, the environmental assessment is limited to greenhouse gas (GHG) emissions, although the methodology outlined can include all other environmental impact categories available in life cycle impact assessment (LCIA) methods. The GHG emissions were calculated based on the GWP100 using CML 2015 LCIA methodology. All life cycle inventory (LCI) data is developed from LCI databases such as Ecoinvent [26] and relevant data and input from literature. For products not available from LCI databases, the methodology developed in Blocket [27] was followed to estimate the GHG emissions for producing typical products shared. See Supplementary Materials and subsequent text for further information.

\subsection{Sharing Services in Hammarby Sjöstad, Stockholm}

This study focuses on the use of a P2P sharing platform within the urban district of Hammarby Sjöstad in Stockholm, Sweden; located on the southern edge of Stockholm with a population of approximately 25,000 inhabitants. The district has long been a test-bed for the experimentation of innovative environmental technologies and urban symbiosis strategies (see reference [28]). Recently the district has become a test-bed for collaborative consumption, as part of the Sharing Cities Sweden program that aims to develop sharing economy test-beds, sharing services and digital solutions, and evaluate the opportunities and risks of the sharing economy. The sharing services that will be developed in the test-beds relate to 1) the utilization of spaces (premises, housing, green infrastructure, shared public space, etc.) and 2) the utilization of goods and services (tools, clothing, toys, handicrafts, etc.).

This study is focused on the environmental potential of an online P2P sharing service provided by the Swedish firm Hygglo (www.hygglo.se) in the outlined urban district. The services provided by Hygglo allow for peer-to-peer sharing of products and services to allow for private individuals to share products that are not used on a regular daily basis for a defined period agreed upon between the provider and the user, where Hygglo facilitates the transactions between the user and provider. Hygglo provides a large number of products, over 7000 listings annually (in 2017) with the largest market in the metro Stockholm area. In this study, the environmental implications of this service were reviewed only for the Hammary Sjöstad district and scenarios were created to review common products currently shared to a baseline scenario where no products are shared. Further details on the products shared and data collection from Hygglo are provided in the Sharing Scenario section below.

This article does not attempt to provide a review of the demographics of the region, the implications of the sharing service on Hammarby Sjöstad residents, nor does it provide an account for behavioral changes, etc. in the region; although the discussion section outlines such aspects which may be important for further research. Hence, the study reviews only the potential of sharing services by assuming they are increased and improved in the region.

\subsection{Scenarios}

In order to assess the implications of P2P collaborative consumption in the Hammarby Sjöstad urban area, scenarios were developed to test a baseline and compare it to sharing, including different assumptions. Thereafter, an integrated logistic service, using a locker sharing service, was added to find the implications on the logistics and transportation impacts. 


\subsubsection{Baseline Scenario}

Assuming that no sharing service was available, a baseline scenario was developed to show the potential benefits of collaborative consumption. In this scenario, all products are purchased and used by residents in the Hammarby Sjöstad area, with varying degrees of use during one year; see Table 1 .

Table 1. Review of the baseline scenario.

\begin{tabular}{cccc}
\hline Products & Number & Unit & Number of Uses \\
\hline Skis (Adult) & 3 & days & 2 \\
Skis (Children) & 3 & days & 2 \\
Electric Tool (w/o battery), e.g., table saw & 20 & $\mathrm{~min}$ & 20 \\
Electric Tool (w/o battery), e.g., circle saw, drill & 29 & $\mathrm{~min}$ & 20 \\
Electric Tool (w / battery), drill & 20 & $\mathrm{~min}$ & 20 \\
Van & 5 & $\mathrm{~km}$ & 100 \\
Car (Combi) & 5 & $\mathrm{~km}$ & 200 \\
Car (Compact) & 5 & $\mathrm{~km}$ & 200 \\
Video Game Unit & 60 & $\mathrm{~min}$ & 100 \\
Bicycle & 10 & $\mathrm{~km}$ & 300 \\
Cargo Bike & 10 & $\mathrm{~km}$ & 300 \\
Cooking Equipment & & & 150 \\
\hline
\end{tabular}

\subsubsection{Sharing Scenario}

The review of the sharing scenario involves the Hygglo P2P platform that enables the collaborative consumption of products [29]. In this study, the environmental impacts of this service were analyzed for the sharing of products in the Hammarby Sjöstad urban district. Scenarios were developed to analyze the most common products currently shared with a baseline where no products are shared.

Data for the most popular products shared and the product searches for Hammarby Sjöstad residents was provided by Hygglo for the period of August 2017 to November 2017. Based on the data provided, an extrapolation to an annual rental lineup of products was made in order to understand the potential of sharing during a longer period. Table 2 outlines the annual rentals and the products reviewed.

Table 2. Annual rentals.

\begin{tabular}{ccc}
\hline Products & Rentals & Number of Listings \\
\hline Skis (Adult) & 132 & 44 \\
Skis (Children) & 132 & 44 \\
Electric Tool (w /o battery), e.g., table saw & 72 & 24 \\
Electric Tool (w / o battery), e.g., circle saw, drill & 12 & 4 \\
Electric Tool (w / battery), drill & 12 & 4 \\
Van & 10 & 3 \\
Car (Combi) & 24 & 8 \\
Car (Compact) & 10 & 3 \\
Video Game Unit & 12 & 4 \\
Bicycle & 48 & 16 \\
Cargo Bike & 12 & 4 \\
Cooking Equipment & 24 & 8 \\
\hline
\end{tabular}

It was assumed that each product would be shared at least three times per year. Thus, the number of products available (listings) is lower than the number of rentals. The following sub-sections provide data and assumptions pertaining to transportation, use and product lifetime, sharing platform and infrastructure and avoided products. 
Transportation for Shared Products/Services

The products shared via the Hygglo platform are assumed to be transported within a short distance from the provider to the user; a maximum distance of approximately $10 \mathrm{~km}$ based on a review of available products in the region. The assumptions on transport mode and distance were included to analyze the sensitivity of the transportation phase; see Table 3. This includes sensitivity to the choice of "high-impact" transportation methods and "low-impact" transportation methods.

Table 3. Transportation of shared products for high and low transport assumptions.

\begin{tabular}{|c|c|c|c|c|c|c|c|c|}
\hline \multirow{2}{*}{ Product } & \multicolumn{4}{|c|}{ High-Impact Transport } & \multicolumn{4}{|c|}{ Low-Impact Transport } \\
\hline & Mode & $\mathbf{k m}$ & Mode & $\mathrm{km}$ & Mode & km & Mode & km \\
\hline Skis (Adult) & Car & 7 & Bus & 3 & Bus & 6 & Bike/walk & 4 \\
\hline Skis (Children) & Car & 7 & Bus & 3 & Bus & 6 & Bike/walk & 4 \\
\hline Electric Tool (w/o battery), e.g., table saw & Car & 7 & Bus & 3 & Bus & 6 & Bike/walk & 4 \\
\hline Electric Tool (w/o battery), e.g., circle saw, drill & Car & 7 & Bus & 3 & Bus & 6 & Bike/walk & 4 \\
\hline Electric Tool (w/battery), drill & Car & 7 & Bus & 3 & Bus & 6 & Bike/walk & 4 \\
\hline Van & Car & 7 & Bus & 3 & Bus & 6 & Bike/walk & 4 \\
\hline Car (Combi) & Car & 7 & Bus & 3 & Bus & 6 & Bike/walk & 4 \\
\hline Car (Compact) & Car & 7 & Bus & 3 & Bus & 6 & Bike/walk & 4 \\
\hline Video Game Unit & Car & 7 & Bus & 3 & Bus & 6 & Bike/walk & 4 \\
\hline Bicycle & Car & 7 & Bus & 3 & Bus & 6 & Bike/walk & 4 \\
\hline Cargo Bike & Car & 7 & Bus & 3 & Bus & 6 & Bike/walk & 4 \\
\hline Cooking Equipment & Car & 7 & Bus & 3 & Bus & 6 & Bike/walk & 4 \\
\hline
\end{tabular}

\section{Product Use and Lifetime}

The use of the product, both by the provider and user, accounted for the varying characteristics and impacts from different products, including e.g. seasons, energy use, etc.; see Table 4. Product use in Hammarby Sjöstad was only considered to allow for a comparison with the reference scenario. It was assumed that $40 \%$ of the products and only $20 \%$ of the vehicles (cars and vans) were available in Hammarby Sjöstad. Thus, only this share of impacts from the use by providers was allocated to the total impacts from the use phase in Hammarby Sjöstad; the sensitivity of this assumption was also tested in the analysis. The assumptions are provided in high and low values to determine the sensitivity of the use phase.

Table 4. Review of the number of uses (high and low assumptions) and respective details for different products shared.

\begin{tabular}{|c|c|c|c|c|c|c|c|}
\hline \multirow{2}{*}{ Replaced Product/Serv } & \multirow{2}{*}{$\begin{array}{l}\text { Provider } \\
\text { (Uses) }\end{array}$} & \multicolumn{3}{|c|}{ Shared Number of uses (High) } & \multicolumn{3}{|c|}{ Shared Number of uses (Low) } \\
\hline & & User (Uses) & Per Use & Unit & User (Uses) & Per Use & Unit \\
\hline Skis (Adult) & 1 & 5 & - & - & 2 & - & - \\
\hline Skis (Children) & 1 & 5 & - & - & 2 & - & - \\
\hline Electric Tool (w/o battery), e.g., table saw & 8 & 5 & 20 & $\min$ & 20 & 20 & $\min$ \\
\hline Electric Tool (w/o battery), e.g., circle saw, drill & 8 & 5 & 20 & $\min$ & 20 & 20 & $\min$ \\
\hline Electric Tool (w/battery), drill & 8 & 5 & 20 & $\min$ & 20 & 20 & $\min$ \\
\hline Van & 20 & 5 & 5 & $\mathrm{~km}$ & 100 & 5 & $\mathrm{~km}$ \\
\hline Car (Combi) & 40 & 5 & 5 & $\mathrm{~km}$ & 200 & 5 & $\mathrm{~km}$ \\
\hline Car (Compact) & 40 & 5 & 5 & $\mathrm{~km}$ & 200 & 5 & $\mathrm{~km}$ \\
\hline Video Game Unit & 40 & 5 & 60 & $\min$ & 100 & 60 & $\min$ \\
\hline Bicycle & 120 & 5 & 20 & $\mathrm{~km}$ & 300 & 20 & $\mathrm{~km}$ \\
\hline Cargo Bike & 120 & 5 & 20 & $\mathrm{~km}$ & 300 & 20 & $\mathrm{~km}$ \\
\hline Cooking Equipment & 60 & 5 & - & - & 150 & - & - \\
\hline
\end{tabular}

Note: This is only $40 \%$ of the provider uses.

The product lifetime was used to determine and allocate emissions to the product for the annual use in the Hammarby Sjöstad area. The lifetime of the products was modeled to be the same in the high and low scenarios; see Table 5. 
Table 5. Lifetime of products.

\begin{tabular}{cc}
\hline Replaced Product & Lifetime (Years) \\
\hline Skis (Adult) & 5 \\
Skis (Children) & 5 \\
Electric Tool (w/o battery), e.g., table saw & 5 \\
Electric Tool (w /o battery), e.g., circle saw, drill & 5 \\
Electric Tool (w/battery), drill & 5 \\
Van & 15 \\
Car (Combi) & 15 \\
Car (Compact) & 15 \\
Video Game Unit & 5 \\
Bicycle & 15 \\
Cargo Bike & 15 \\
Cooking Equipment & 4 \\
\hline
\end{tabular}

Platform and Infrastructure for Sharing

The impact of the online sharing platform, e.g., data and energy use for searches, databases, servers, were also considered. It is assumed that there were three searches per listing and that all the products were shared several times. In order to include the impact of the sharing service platform, electricity demand for data storage and search engine use was developed based on details provided in [30-35] (see Supplementary Materials).

\section{Replaced Products}

As a consequence of the sharing platform, consumer behavior may be altered; i.e. the purchase of certain products may be avoided or replaced by the sharing of products with the same functionality. The assumptions for the proportion of products replaced by sharing are detailed in Table 6 .

Table 6. Review of the number of replaced products due to sharing (high and low assumptions).

\begin{tabular}{|c|c|c|c|c|}
\hline \multirow{2}{*}{ Replaced Product } & \multicolumn{2}{|c|}{ High } & \multicolumn{2}{|c|}{ Low } \\
\hline & Replace (\%) & Replaced Prods. & Replace (\%) & Replaced Prods. \\
\hline Skis (Adult) & $50 \%$ & 66 & $25 \%$ & 33 \\
\hline Skis (Children) & $50 \%$ & 66 & $25 \%$ & 33 \\
\hline Electric Tool (w/o battery), e.g., table saw & $50 \%$ & 36 & $25 \%$ & 18 \\
\hline Electric Tool (w/o battery), e.g., circle saw, drill & $50 \%$ & 6 & $25 \%$ & 3 \\
\hline Electric Tool (w/battery), drill & $50 \%$ & 6 & $25 \%$ & 3 \\
\hline Van & $1 \%$ & 1 & $1 \%$ & 1 \\
\hline Car (Combi) & $11 \%$ & 3 & $5 \%$ & 1 \\
\hline Car (Compact) & $11 \%$ & 1 & $5 \%$ & 1 \\
\hline Video Game Unit & $50 \%$ & 6 & $25 \%$ & 3 \\
\hline Bicycle & $50 \%$ & 24 & $25 \%$ & 12 \\
\hline Cargo Bike & $50 \%$ & 6 & $25 \%$ & 3 \\
\hline Cooking Equipment & $50 \%$ & 12 & $25 \%$ & 6 \\
\hline
\end{tabular}

\subsubsection{Integrated Scenario for Improved Logistics through the Sharing Locker Service}

As the transportation of products between the provider and user have been found to have a significant impact on the environmental performance of sharing products, the potential for the improved logistics of product sharing was also reviewed through integration with a recently developed digital locking and storage service (hereafter referred to as locker service) in Hammarby Sjöstad. It is hoped that this locker service will improve package logistics and availability for P2P sharing. Additional scenarios have therefore been included to assess the influence of such locker services, including assumptions, on product sharing through the P2P platform.

For delivery and pick-up, the sender can put the package in a locker and register it with the service; thereafter the recipient is notified through a mobile application, and the postbox, locker or room, can be opened using the application or code. By providing such services, households and citizens can share 
products among themselves, and logistics companies can deliver and pick-up packages with a reduced number of delivery attempts. The sharing locker service can be used for the sharing of products; as such the services were also reviewed in this assessment as a separate service and in integration with the online sharing platform. This was done to understand the potential for reduced emissions and transportation, first and foremost, from traditional package deliveries.

In order to review the potential of using this system, the review includes the use of the locker services in all apartment buildings in Hammarby Sjöstad. Lockers, with several boxes, were anticipated to be installed as new lockers in the apartment buildings; see Supplementary Materials for more details on the assumptions for the locker service.

For the sharing services reviewed in the previous scenarios, it was assumed that all products were shared personally between the user and provider. With the use of the locker services, traditional logistics may be employed for the sharing of products between the user and provider. To determine the implications of the service integration, all products shared through the online sharing platform in the Hammarby Sjöstad district were modeled as employing the sharing lockers. This entails that the products are placed in a sharing service locker, picked up by a logistics company and thereafter placed in another locker.

Previous products reviewed, which may not be compatible with the locker services, e.g. cars, vans and bikes, were not included in the assessment, as the review was focused only on products which could fit in the lockers. As such, the assessment was dissimilar to the previous scenario reviewed above, and not compared with these results. To compare with the previous P2P sharing scenario (without the sharing of cars, vans and bikes) results were also extracted for the sharing of the remaining products. In the integrated scenario, the transportation of the packages is altered to include pick-up and delivery by logistic services and impacts.

A high and low transportation impact for the logistics was also tested; again, with a total distance of $10 \mathrm{~km}$. The high impact transportation (labeled Sharing Integ. Trans. Logistics) included picking up the package by a conventional diesel vehicle (e.g. Bring or DHL), its distribution to a central logistics center and delivery to the user by cargo bikes. The trip back to the provider was assumed to have the same route. The package, therefore, is posted, picked-up, delivered, posted, and returned using the sharing locker and logistics services.

In the near future, logistic services for the Hammarby Sjöstad urban district aim to use cargo bikes services. As such, no impacts for transport were included for the use of the bikes, although there may be impacts from storage and management of the operations. The low impact transportation scenario (labeled Sharing Integ. Trans. Bike) included only logistics by cargo bikes.

Finally, as the integration may increase sharing due to the ease at which packages can be picked up and dropped off, another scenario was included to review an increase in sharing. In this scenario, the assessment includes twice as many products shared, given the same number of advertisements and availability for sharing (labeled Sharing Integ. Incr. Sharing).

\section{Results and Analysis}

\subsection{Online Sharing Platform}

The sharing services platform showed significant GHG reduction potential compared to the baseline scenario; see Figure 2. In the baseline scenario, the GHG emissions corresponded to roughly $22,000 \mathrm{~kg} \mathrm{CO}_{2}$-eq annually. The sharing scenarios, both high and low, showed emission reduction corresponding to over $18,000 \mathrm{~kg} \mathrm{CO}$-eq. Impacts associated with goods production are reduced in the sharing scenario, as there are fewer products in the system. The impacts from the use phase were also found to decrease in the sharing scenarios, due to an overall reduction in use in the Hammarby Sjöstad area. However, the impacts for the use of the products (including use outside of Hammarby Sjöstad) may increase due to an increased total number of uses of the product (but again less than the baseline scenario, see the analysis). The impacts from the digital infrastructure were found to be 
nearly negligible for the data transmission, storage and energy use for the searching, uploading and storing of information in the sharing scenarios, and were thus included in the use phase. Furthermore, as the study also reviewed the effects that the sharing of products may have on avoiding purchases of similar products, the use of sharing services can lead to even larger benefits (i.e. large credits) if the replacement of products is also included. As such, in Figure 2, the "Total" indicator is the difference between the sum of the impacts from use, production, transport and infrastructure and the credits from avoided purchases.

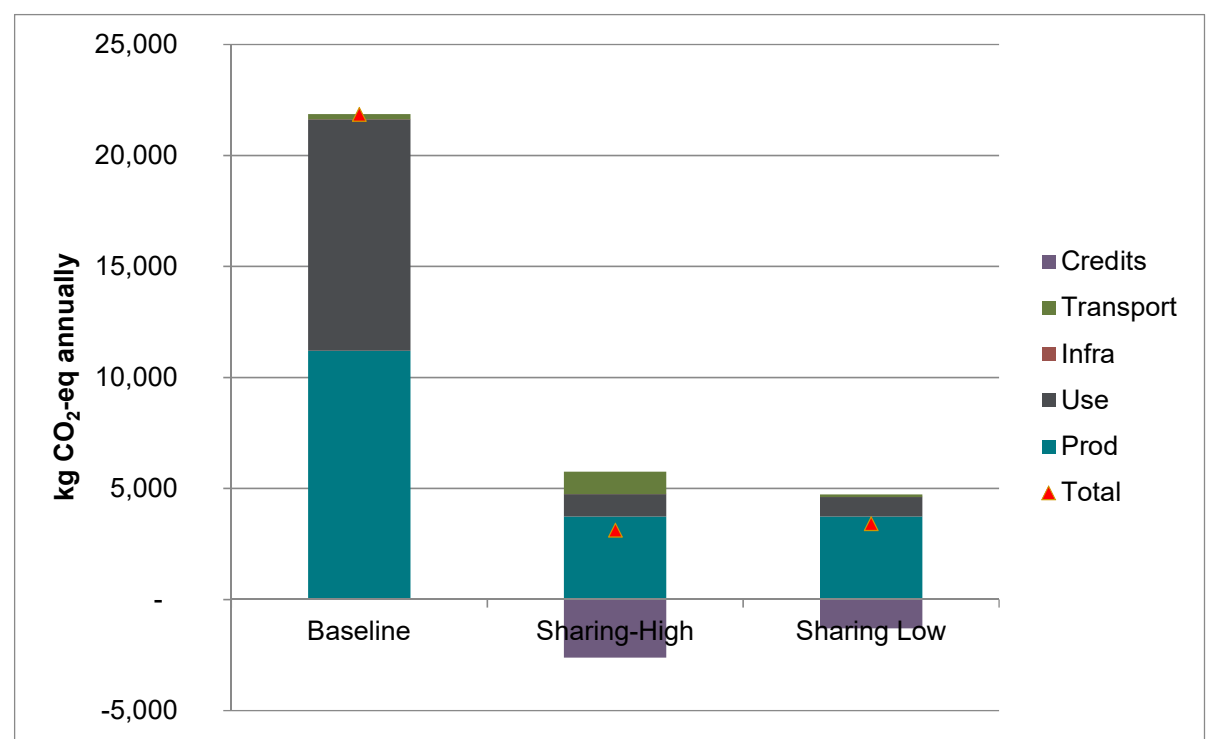

Figure 2. Annual emissions for the reviewed scenarios, including credits for avoided product purchases.

Figure 3 illustrates the total impacts (split once again into credits, transport, use, and production) for the separate products. As shown, it was estimated that the largest impacts may be due to the use of vehicles; which were also only rented a limited number of times. Electricipowered products, such as tools and video game units, displayed very small overall impacts. Due in part to the low number of products rented. See further analysis of the sensitivity to assumptions on the use of the products in subsequent sections.

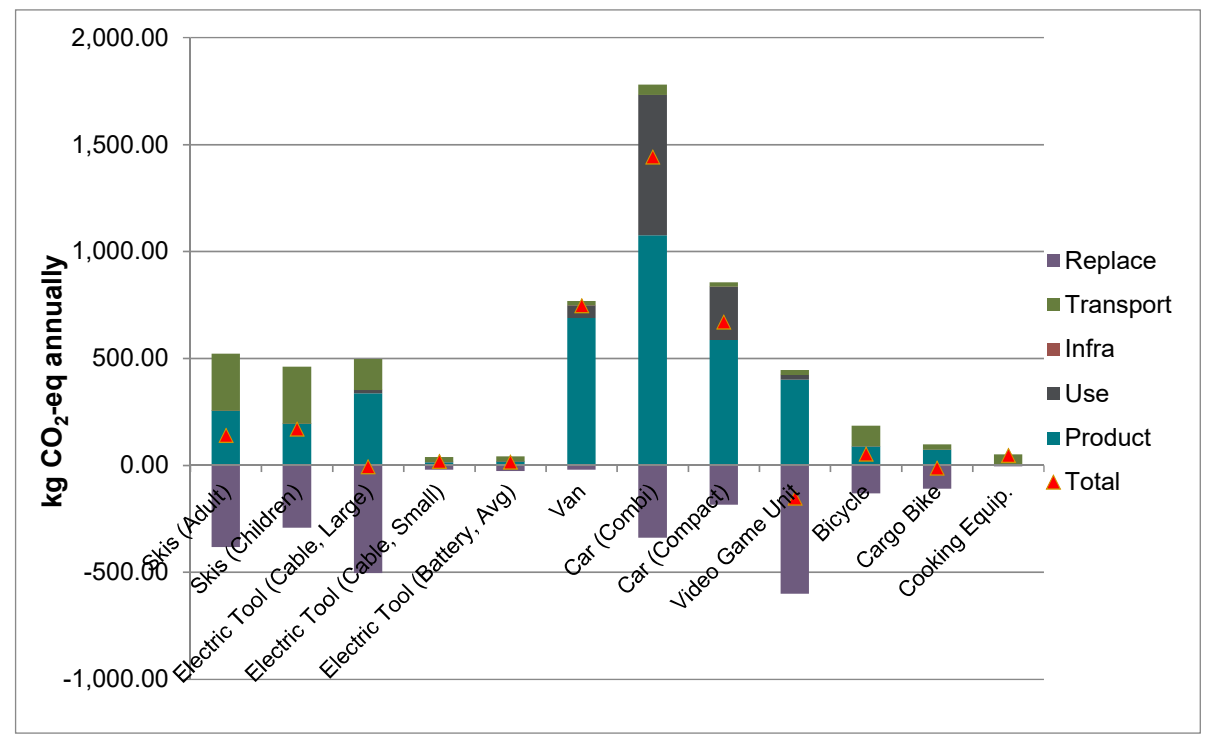

Figure 3. Emissions per product shared for Sharing-High scenario. 
Additionally, Figure 4 illustrates the contribution of the different LCA phases to the overall impact; highlighting the different inherent properties. While some products have little to no impact on the use phase, others have high impacts during their use phase. Interestingly, for several products, a large share of the GHG emissions are from the transportation of the product from the provider to the user (e.g., those products with little to no emissions from the use phase, such as cooking equipment and skis). Again, the use phase impacts of the vehicles are shown to be large in comparison to the other products.

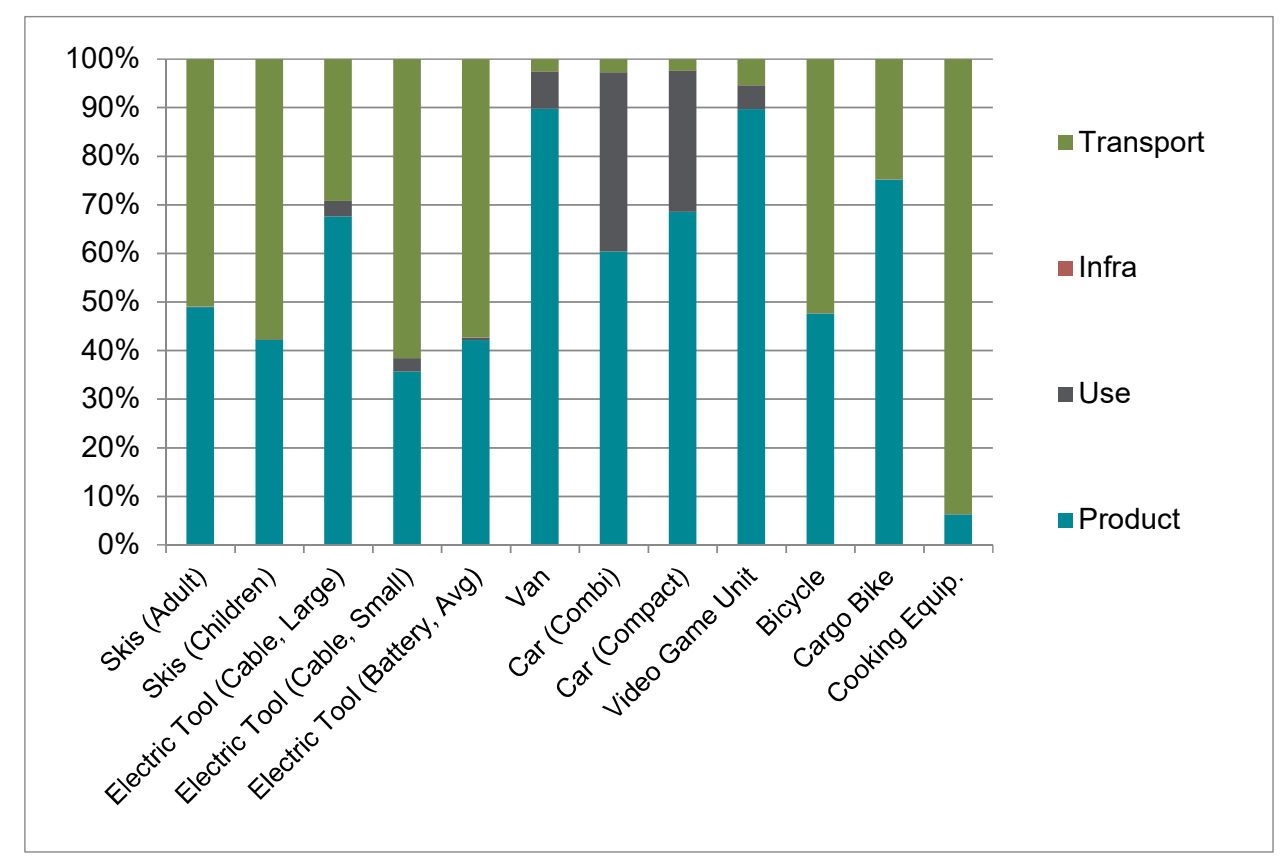

Figure 4. Contribution of different impact categories to overall GHG emissions per product shared for Sharing-High scenario.

Sensitivity to Data and Methodological Choices

The following sub-sections review and analyze the sensitivity of assumptions used in the comparisons; namely, the extent of replaced products, product lifetime, and transportation distance for the shared products.

\section{Replaced Products}

As Figure 5 illustrates, increasing or decreasing the number of products replaced by $50 \%$, can result in large modifications in the overall annual impacts. When increasing the number of conventional products replaced, shown in the Sharing-High Repl. $+50 \%$ scenario, an overall decrease in emissions of $42 \%$ is illustrated. Alternatively, for the Sharing-Low-Repl. $-50 \%$ scenario, a minor increase in emissions is illustrated. 


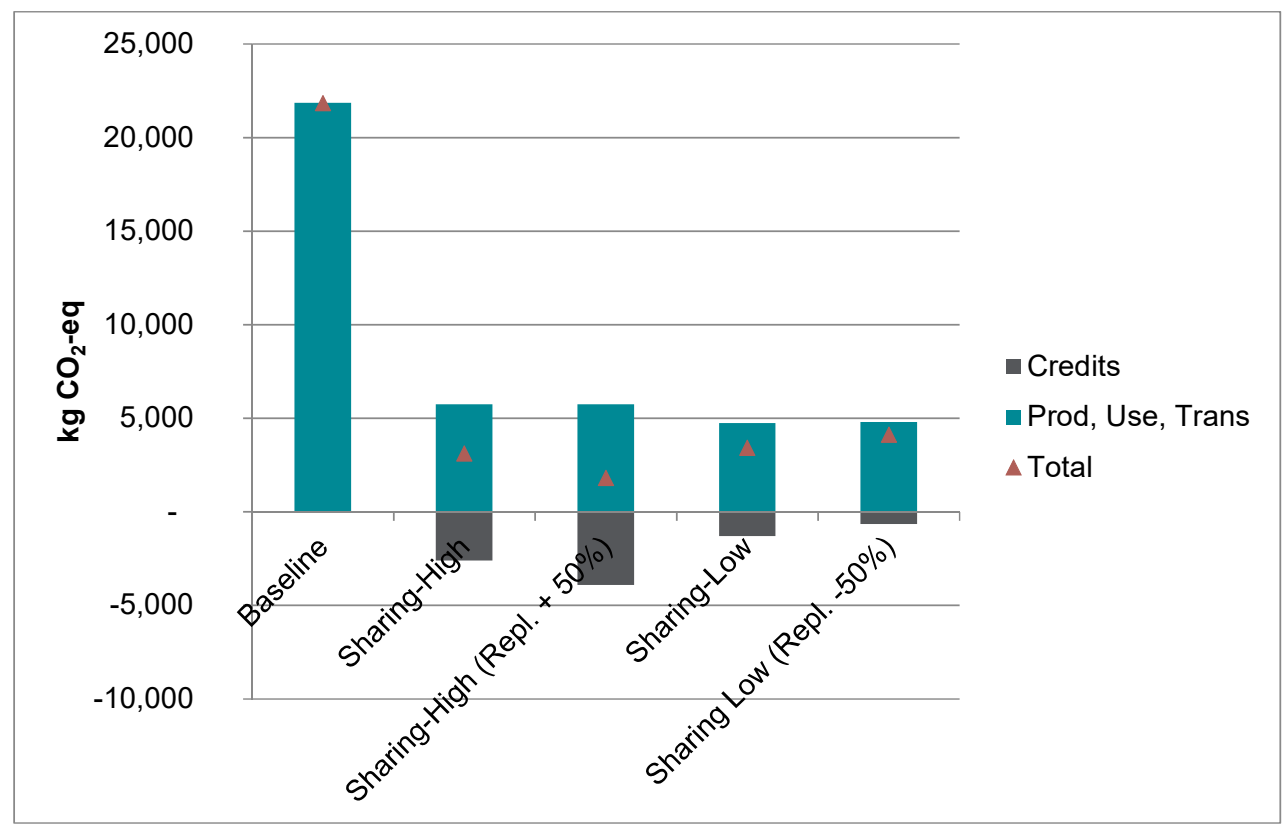

Figure 5. Reviewing the sensitivity for choices in the number of replaced products.

\section{Product Lifetime}

In both the high-use and low-use sharing scenarios, the product lifetime of the shared products was similar to the baseline scenario. However, in the sharing scenarios, the product lifetime may be reduced, due to the exchanging of the products between different users. Thus, by extending the use of the products, it is important to review the effect that this may have on the overall impacts. For the Sharing High (Life) scenario and Sharing Low (Life) the lifetime of the product was decreased and increased by $30 \%$ respectively. As Table 7 illustrates, there is no longer a lower impact for the sharing-high scenario, as the production and use impacts are increased, due primarily to a lower "denominator" for dividing the impacts per year, as the higher use scenario assumes a lower lifetime.

Table 7. Reviewing the influence of the lifetime for products in sharing scenarios (measured in $\mathrm{kg}$ $\mathrm{CO}_{2}$-eq emissions annually).

\begin{tabular}{cccccc}
\hline Phase & Baseline & Sharing-High & Sharing-High (Life) & Sharing-Low & Sharing-Low (Life) \\
\hline Production & 11,200 & 3730 & 5330 & 3730 & 3880 \\
Use & 10,430 & 1000 & 1000 & 880 & 1000 \\
Transport & 240 & 1010 & 1010 & 120 & 120 \\
Credits & & -2620 & -3740 & -1310 & -2010 \\
Total & $\mathbf{2 1 , 8 7 0}$ & $\mathbf{3 1 2 0}$ & $\mathbf{3 6 0 0}$ & $\mathbf{3 4 2 0}$ & $\mathbf{2 9 9 0}$ \\
\hline
\end{tabular}

\section{Distance/Transportation}

The influence of the transportation distance of the shared products to the environmental impacts is also reviewed in Table 8. For the two scenarios, the transportation distance was increased by a factor of 5. In the Sharing High (Trans.) scenario, the distance traveled was increased from 10 to $50 \mathrm{~km}$ roundtrip for products being shared by car and bus, and in the Sharing Low (Trans.) scenario, the distance increased from 5 to $25 \mathrm{~km}$ by bus and walking. Additionally, in the Sharing Low (Trans.) scenario, it was assumed that $90 \%$ of the travel would be done by bus. 
Table 8. Reviewing the influence of transportation distance for sharing scenarios (measured in $\mathrm{kg}$ $\mathrm{CO}_{2}$-eq emissions annually).

\begin{tabular}{cccccc}
\hline Phase & Baseline & Sharing-High & $\begin{array}{c}\text { Sharing-High } \\
\text { (Trans.) }\end{array}$ & Sharing-Low & $\begin{array}{c}\text { Sharing-Low } \\
\text { (Trans.) }\end{array}$ \\
\hline Production & 11,200 & 3730 & 3730 & 3730 & 3730 \\
Use & 10,430 & 1000 & 1000 & 880 & 880 \\
Transport & 240 & 1010 & 5040 & 120 & 290 \\
Credits & & -2620 & -2620 & -1310 & -1310 \\
Total & $\mathbf{2 1 , 8 7 0}$ & $\mathbf{3 1 2 0}$ & $\mathbf{7 1 5 0}$ & $\mathbf{3 4 2 0}$ & $\mathbf{3 5 9 0}$ \\
\hline
\end{tabular}

As illustrated in Table 8, increasing the distance traveled for sharing products between users may lead to increased GHG emissions. In the Sharing-High (Trans.) scenario, the total impacts are increased by roughly $130 \%$, while the transportation impacts being increased by over $400 \%$. In the Sharing-Low (Trans.) scenario, no significant increases in total impacts were illustrated (an increase of roughly 9\%) although there was an increase in transportation impacts of roughly $150 \%$.

Use of the Products

In this study, impacts from the providers are also included; although this only included impacts for those providers in Hammarby Sjöstad, which was assumed to be $40 \%$ of the products. The sensitivity to this choice, including all impacts from users within and outside Hammarby Sjöstad, are reviewed in Figure 6. The results illustrate that including the use by providers outside of the area may significantly increase the environmental impacts. As such, the use phase adds to a large share of the impacts of the products being shared compared to the Sharing-High and Sharing-Low scenarios, as outlined earlier. Nonetheless, compared to the reference scenario, the emissions are still significantly lower.

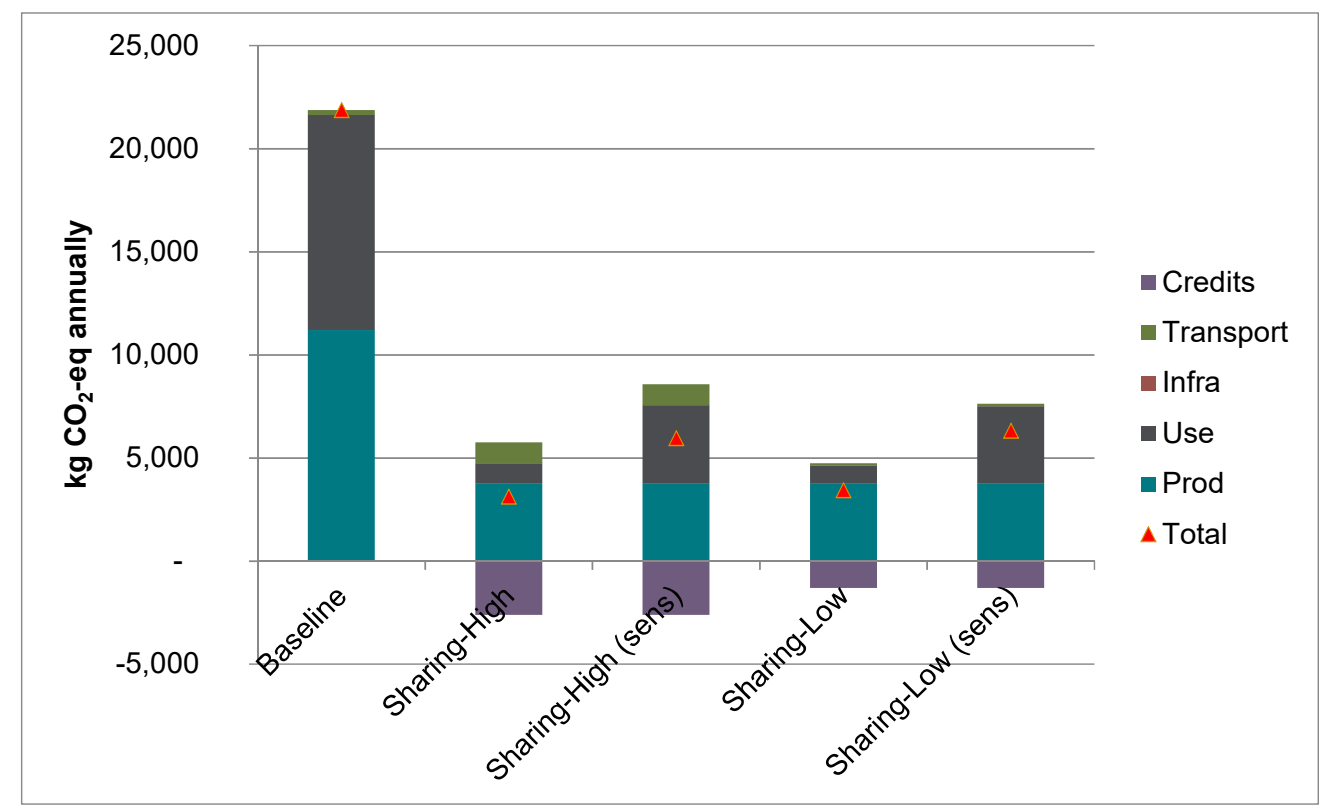

Figure 6. Sensitivity to the use by the providers. Sharing High (sens) and Sharing-Low (sens) show inclusion of all impacts for use by providers (both providers within and outside of Hammarby Sjöstad). Other sharing scenarios show only the impacts from use by providers in Hammarby Sjöstad.

\subsection{Integration with Locker Services}

Figure 7 illustrates that there is significant potential to reduce impacts from sharing services through integration of the sharing platform, locker services, and improved transportation logistics. Comparing the Sharing-Ref-High scenario with the Sharing Integ. Def. Logistics scenario, a large 
reduction in impacts from transportation is illustrated. This is due to the integration of using sharing lockers and logistics services with the online sharing platform. Transportation emissions are drastically reduced in the Sharing Integ. Trans Bike scenario, as all transports were modeled to take place with cargo bikes. In the final scenario reviewed, Sharing Integ. Incr. Sharing, it was assumed that an increase in sharing may be possible due to the ease at which packages can be picked up and dropped off. Thus, there is a large potential to replace purchases of conventional products with the same range of products available for sharing. As with the other scenarios, these may also be sensitive to the choice of data and assumptions, although they are not reviewed again.

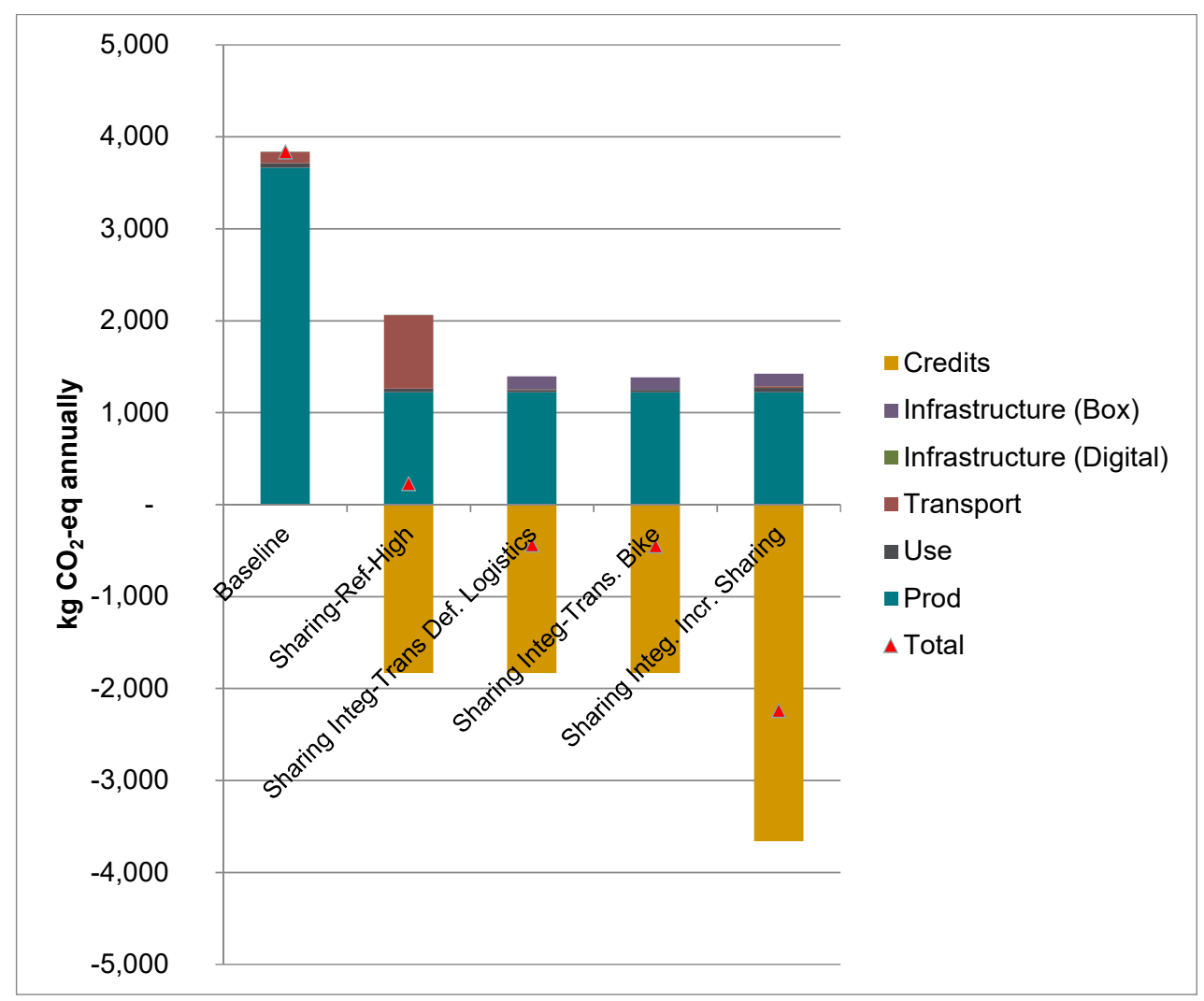

Figure 7. Comparison of baseline impacts with sharing scenarios from Hygglo (Sharing-Ref) and with Hygglo and QLocx integration (Sharing Integrated).

\section{Discussion}

The results presented show significant benefits from the use of sharing services compared to conventional consumption and logistic methods. While there are few studies that assess the environmental impacts from sharing services, the results correspond with several previous studies that analyze the impacts of sharing and logistics [12,18,36,37]. However, it should be noted that these results could be over- or underestimations of the potential impact reductions, as the results are sensitive to the assumptions made for important methodological considerations, such as product impacts, avoided product purchases and transportation methods and distance; as reviewed in the sensitivity to choices above.

\subsection{Products and Avoided Purchases}

As shown, significant changes in overall impacts are apparent when comparing the consequences of sharing to a baseline. The impacts of production contribute to a large share of the impacts in all scenarios; with significant emission reductions present when comparing baseline and sharing scenarios. 
The use of products, on the other hand, contributes to a relatively minor share of the overall impacts from the products being shared.

The benefits of avoiding the purchase of new products were illustrated to have a significant influence on the results. When using system expansion methods, this choice, and ultimately the system boundaries of the study, has a significant impact on the overall impact of the systems being reviewed; see discussion on avoided impacts in the LCA literature [38-41]. However, few assessments review the avoided impacts from sharing contrasted with conventional consumption models [22,40]. Furthermore, while sharing services have the potential to avoid the purchase of new products, there is a lack of studies in the literature documenting such behavioral changes, despite studies identifying the social and economic motives for using sharing services $[8,42,43]$.

\subsection{Product Use and Lifetime}

The results suggest that the use phase for many of the products contribute to a minor share of impacts. Many of the products used had little to no impact from the use phase, as there was no material or energy inputs for their use. For electrical products, this may be sensitive to the datasets used. As this study was conducted in Sweden, the Ecoinvent dataset for Swedish electricity mix was used. However, previous studies have shown sensitivity to the use of e.g. Nordic electricity mix data (see e.g., [44]). Additionally, as identified in previous studies, many products designed with a long service life, rarely are used to their potential [45]. As Kjaer et al. [40] suggest for research related to providing product services, there are many challenges to assess the impacts from the use phase, as the products may require maintenance and refurbishment; although the aforementioned study is not concerned with P2P platforms, many parallels can be drawn to product-service system research.

\subsection{Transportation and Integrating Services}

The assumptions for the transportation of the products from the provider to the user also had a significant influence on product sharing impacts; supporting the results of Leismann et al. [18] and Zamani et al. [12]. While Zamani et al. [12] discuss the potential for postal service options for such web-based sharing platforms, they were not reviewed. This study included transportation by car, bus, bike and walking, and thereafter logistic services; which showed aa significant potential for reduced GHG emissions through improved postal logistics; supporting the claims of Zamani et al. [12]. In the scientific literature, there is limited availability of such reviews. This study provides a unique perspective for the potential of integrating sharing services. The results suggest that this could greatly reduce the impacts from the online sharing platform, and potentially lead to increased sharing.

\subsection{Impacts of Online Services}

Although identified as a minor impact in this study, due to the limited geographical proximity and volume of products shared, with an increase in web-based sharing platforms and services in the future, it will be important to review the potential impacts created by the use of the web-based services for data transfer, storage, etc. However, such concerns are insufficient in the literature. In a study by Suckling and Lee [46], they found that the addition of phones, and their use of internet services, will require more and more servers and data storage platforms in the future. At the time, they estimate that the data usage of roughly 400 phones (based on data use at the time) per server would be required. As Malmodin et al. [30] discuss, Sweden has the highest data traffic per capita in the world, and this continues to increase. Nonetheless, as phones, servers, cloud services, etc. become increasingly efficient and multi-functional, the review of such impacts may also provide an additional obstacle to overcome in order to allocate impacts; see, e.g., [47]. van Loon [48] also reviews the impact of retail and suggests that improvements may be needed to review the actual impacts occurring, not only from the use but also from the rebound effects. Börjesson-Rivera et al. [49] suggest that available metrics for reviewing the impacts from servers and the use of internet is difficult, and many available figures for carbon emissions are very dissimilar. 
In studies such as Blocket [27], internet use for users is not included, but the impacts for energy use for the entire company (including servers) is included, as it was difficult to review other impacts. It is important that such information is made more transparent (and included) in assessments to show the impacts of internet-based sharing systems, as they are becoming more popular.

\subsection{Sustainability and Rebound Effects}

There are few assessments to review the actual implications of the sharing economy; and even fewer reviewing systems that target the sharing of resources in P2P platforms (see e.g., [23]). Aside from the discourse and speculations on the potential environmental improvements, the empirical evidence is scarce and it is extremely challenging and complex to demonstrate the potential environmental improvements at an aggregate level; see [50]. As such, first-order effects, such as those reviewed in this study may be possible to review, but the net impact at an aggregated socio-economic level should also be considered; see, e.g., [37].

While this study assumed that the availability of the sharing services may increase its use, and the potential replacement of conventional products and processes in response, as Parguel et al. [23] emphasize, the availability of $\mathrm{P} 2 \mathrm{P}$ platforms may contribute to more indulgent consumption patterns. This can transpire due to the money saved by sharing; which was found to be a primary driver for users of sharing services [42]. If the additional wealth (saved) is instead spent on other energy or carbon-intensive products or services, there may be an increase in environmental impacts. Many people also engage in sharing, not only due to the environmental impacts, but the community, social and economic benefits; see e.g., [8,42,43,51]. However, social and economic sustainability are rarely addressed. There is, therefore, a need, and currently a lack of studies, for broader sustainability assessments with the increased use of sharing services and other collaborative economy models [52].

\subsection{System Boundaries and Data}

The results of this study are largely reliant upon life cycle inventory data for the products and logistics reviewed; which are currently lacking. As such, the project relies on data developed on the basis of material specifications and other databases for representative data, e.g., Ecoinvent v. 3.3; which may over- or underestimate the emissions from the products reviewed. However, the robustness of such assessments would be improved with a broader range of product data.

Furthermore, this study does not handle the impacts from the waste handling of the products. The downstream impacts may also be important to understand, given the potential for extending the lifetime of products, in terms of uses; which is an important limitation to highlight. In future assessments, it will be important to understand the implications this may have for a reduction in potential material flows (i.e. circular material flows), energy recovery from waste incineration, etc.

The study also is limited to data provided from Hygglo on shared products and the listing for the Hammarby Sjöstad region. As such, it may not represent, nor be applicable to other regions in Stockholm; thus, leading to over or underestimations of the actual benefits from sharing if used in a wider context.

\section{Conclusions}

This paper has provided an approach for quantifying the environmental performance of sharing services using a life cycle assessment. For P2P services, this includes important factors such as the production, use, product lifetime, logistics and transportation of products between user and provider, digital sharing infrastructure, and avoided conventional products linked to the sharing of products.

Using the methodological considerations for the environmental assessment, the results of this study indicate that there is a significant potential for sharing services to reduce environmental impacts of consumption in the Hammarby Sjöstad urban district. The online P2P sharing platform can promote reduced production impacts by avoiding new product purchases and extending the service life of underutilized products in the area. Compared to the baseline scenario, over 18 tonnes of 
$\mathrm{CO}_{2}$-eq emissions can be reduced by sharing a limited number of products in the small urban area of Hammarby Sjöstad using one P2P sharing platform.

The use the products shared was determined to have little influence on the results, except for shared vehicles. The transportation of the products from provider to the user had a significant influence on the results. The avoidance of product purchases illustrated significant performance improvement potential, with assumptions of a high product avoidance leading to an additional 2 tonnes $\mathrm{CO}_{2}$-eq emissions reduction. The synergies with the locker service can also further reduce impacts of the transportation of products between the provider and user. This is accomplished by providing an increased availability for delivery and pick-up services to promote sharing through improved logistics. Once again, however, and as reviewed in the analysis, the results are dependent upon a number of assumptions and are sensitive to methodological choices made in the modeling, e.g., to transportation methods of the products, the number of uses and avoided purchases of new products. The assessment does not cover the waste management of the products nor the demographic conditions in the region for promoting further sharing and integrated sharing services. Nonetheless, while the study provides a review in only one district of Stockholm, the results have shown significant improvements from the limited sharing of products in the district.

In conclusion, the study outlines a methodology that can be employed for reviewing the environmental performance of sharing services and highlights many of the potentially sensitive methodological choices and areas for improvement when reviewing the impacts of sharing services.

\section{Future Research Suggestions}

This study has provided a review of P2P sharing and its environmental performance. Further studies such as this are welcomed in the scientific literature to compare and analyze the implications of sharing services and the importance of methodological considerations.

Further research is needed on how P2P sharing platforms influence users' consumption patterns. With the proliferation of P2P platforms, it will be important to assess behavioral changes as the sharing would become more accessible [53].

Furthermore, while the demographics and pre-conditions have not been explored, nor its influence on sharing, for the Hammarby Sjöstad urban district, this may be important to review further, as the residents are generally of higher economic status than other areas in Stockholm (and Sweden) [28], and have been subject to a number of sustainability targeted initiatives [54], which may influence the use of P2P services [55].

This study also reviewed the integration of P2P services with other logistic services. Assessments may need to include economic aspects to review the added costs for sharing incurred by further integrated systems; e.g. business models and costs for optimized value.

Supplementary Materials: The following are available online at http:/ / www.mdpi.com/2071-1050/11/1/190/ s1.

Author Contributions: M.M. conceived of and designed the research approach for the project. M.M. also contributed to the development of methods, primary data collection for LCI data in addition to the environmental analysis and the majority of the writing. D.L. contributed with a literature review of sharing economy and collaborative consumption literature, writing in the text and provided a critical review, analysis of the data, the development of scenarios, figures, writing of the text and revisions. C.G. provided support for the project through contacts with sharing service providers, data collection and a review of the manuscript.

Funding: This project has been funded through Sharing Cities Stockholm, which is an initiative within Viable Cities (www.viablecities.com), the Swedish Strategic Innovation Program for smart, sustainable cities. The program is jointly funded by the Swedish Innovation Agency (VINNOVA), the Swedish Energy Agency and the Swedish Research Council for Environment, Agricultural Sciences and Spatial Planning (FORMAS).

Acknowledgments: The authors would like to thank Jonatan Wranne for his help with the LCI data used in this project and input from the sharing service provider Hygglo. We are also grateful for the constructive input from the reviewers and editors.

Conflicts of Interest: The authors declare no conflict of interest. 


\section{References}

1. Acquier, A.; Daudigeos, T.; Pinkse, J. Promises and paradoxes of the sharing economy: An organizing framework. Technol. Forecast. Soc. Chang. 2017, 125, 1-10. [CrossRef]

2. Gruszka, K. Framing the collaborative economy-Voices of contestation. Environ. Innov. Soc. Transit. 2016. [CrossRef]

3. Botsman, R.; Rogers, R. What's Mine is Yours: How Collaborative Consumption is Changing the Way We Live; Collins: London, UK, 2011.

4. Rifkin, J. The Zero Marginal Cost Society: The Internet of Things, the Collaborative Commons, and the Eclipse of Capitalism; Palgrave Macmillan: London, UK, 2014.

5. Martin, C.J. The sharing economy: A pathway to sustainability or a nightmarish form of neoliberal capitalism? Ecol. Econ. 2016, 121, 149-159. [CrossRef]

6. Heinrichs, H. Sharing economy: A potential new pathway to sustainability. GAIA Ecol. Perspect. Sci. Soc. 2013, 22, 228-231. [CrossRef]

7. Hoekstra, A.Y.; Wiedmann, T.O. Humanity's unsustainable environmental footprint. Science 2014, 344, 1114-1117. [CrossRef]

8. Böcker, L.; Meelen, T. Sharing for people, planet or profit? Analysing motivationsfor intended sharing economy participation. Environ. Innov. Soc. Transit. 2017, 23, 28-39. [CrossRef]

9. Boons, F.; Bocken, N. Towards a sharing economy-Innovating ecologies of business models. Technol. Forecast. Soc. Chang. 2018. [CrossRef]

10. Sprei, F.; Ginnebaugh, D. Unbundling cars to daily use and infrequent use vehicles-the potential role of car sharing. Energy Effic. 2018, 11, 1433-1447. [CrossRef]

11. Jung, J.; Koo, Y. Analyzing the Effects of Car Sharing Services on the Reduction of Greenhouse Gas (GHG) Emissions. Sustainability 2018, 10, 539. [CrossRef]

12. Zamani, B.; Sandin, G.; Peters, G.M. Life cycle assessment of clothing libraries: Can collaborative consumption reduce the environmental impact of fast fashion? J. Clean. Prod. 2017, 162, 1368-1375. [CrossRef]

13. Iran, S.; Schrader, U. Collaborative fashion consumption and its environmental effects. J. Fash. Market. Manag. 2017, 21, 468-482. [CrossRef]

14. Dornier, R.; Selmi, N. Peer-to-peer accommodation and sustainability in mountain areas. Worldwide Hospital. Tour. Themes 2018, 10, 259-266. [CrossRef]

15. Tussyadiah, I.P.; Pesonen, J. Impacts of Peer-to-Peer Accommodation Use on Travel Patterns. J. Travel Res. 2016, 55, 1022-1040. [CrossRef]

16. Ala-Mantila, S.; Ottelin, J.; Heinonen, J.; Junnila, S. To each their own? The greenhouse gas impacts of intra-household sharing in different urban zones. J. Clean. Prod. 2016, 135, 356-367. [CrossRef]

17. Underwood, A.; Fremstad, A. Does sharing backfire? A decomposition of household and urban economies in $\mathrm{CO}_{2}$ emissions. Energy Policy 2018, 123, 404-413. [CrossRef]

18. Leismann, K.; Schmitt, M.; Rohn, H.; Baedeker, C. Collaborative Consumption: Towards a Resource-Saving Consumption Culture. Resources 2013, 2, 184. [CrossRef]

19. Mont, O. Reducing life-cycle environmental impacts through systems of joint use. Green. Manag. Int. 2004, 45, 63-77. [CrossRef]

20. Clewlow, R.R.; Mishra, G.S. Disruptive Transportation: The Adoption, Utilization, and Impacts of Ride-Hailing in the United States; Institute of Transportation Studies, University of California: Davis, CA, USA, 2017.

21. Briceno, T.; Peters, G.; Solli, C.; Hertwich, E. Using Life Cycle Approaches to Evaluate Sustainable Consumption Programs: Car-Sharing; Working Papers from Industrial Ecology Programmme (IndEcol); NTNU: Trondheim, Norway, 2005; pp. 1504-3681.

22. Agrawal, V.V.; Ferguson, M.; Toktay, L.B.; Thomas, V.M. Is leasing greener than selling? Manag. Sci. 2012, 58, 523-533. [CrossRef]

23. Parguel, B.; Lunardo, R.; Benoit-Moreau, F. Sustainability of the sharing economy in question: When second-hand peer-to-peer platforms stimulate indulgent consumption. Technol. Forecast. Soc. Chang. 2017, 125, 48-57. [CrossRef]

24. Cohen, B.; Muñoz, P. Sharing cities and sustainable consumption and production: Towards an integrated framework. J. Clean. Prod. 2016, 134, 87-97. [CrossRef] 
25. Finnveden, G.; Hauschild, M.Z.; Ekvall, T.; Guinée, J.; Heijungs, R.; Hellweg, S.; Koehler, A.; Pennington, D.; Suh, S. Recent developments in Life Cycle Assessment. J. Environ. Manag. 2009, 91, 1-21. [CrossRef] [PubMed]

26. Ecoinvent. The Ecoinvent Database v 3.3. Zurich, Switzerland, 2016. Available online: https://www.ecoinv ent.org/database/ecoinvent-33/ecoinvent-33.html (accessed on 28 January 2017).

27. Blocket. Begagnathandelns Klimatnytta. 2013. Available online: http:/ /www.ivl.se/download/18.422aa27 a15260b0160f1a4/1453820203582/Beg.handel_klimatnytta_rapport.pdf (accessed on 5 November 2018).

28. Pandis Iverroth, S. Industrial Ecology for Sustainable Urban Development-The Case of Hammarby Sjöstad. Ph.D. Thesis, KTH-Royal Institute of Technology, Stockholm, Sweden, 2014.

29. Hygglo. Personal Communication with Hygglo.se about Data for Sharing, Products, etc. January 2018. Available online: www.hygglo.se (accessed on 5 November 2018).

30. Malmodin, J.; Lundén, D.; Moberg, Å.; Andersson, G.; Nilsson, M. Life Cycle Assessment of ICT. J. Ind. Ecol. 2014, 18, 829-845. [CrossRef]

31. Malmodin, J.; Lundén, D. The Energy and Carbon Footprint of the ICT and EEM Sector in Sweden 1990-2015 and Beyond; Advances in Computer Science Research; ICT for Sustainability: Amsterdam, The Netherlands, 2016.

32. Costenaro, D.; Duer, A. The Megawatts behind Your Megabytes: Going from Data-Center to Desktop. ACEEE Summer Study on Energy Efficiency in Buildings. Available online: https:/ /aceee.org/files/proceed ings/2012/data/papers/0193-000409.pdf (accessed on 24 December 2018).

33. Google. Powering a Google Search. 2009. Available online: https://googleblog.blogspot.se/2009/01/power ing-google-search.html (accessed on 5 November 2018).

34. Google. Google Official Blog. Gmail, It's Cooler in the Cloud. 2014. Available online: https://googleblog.b logspot.se/2011/09/gmail-its-cooler-in-cloud.html (accessed on 5 November 2018).

35. Apple. IPhone 7 Environmental Report. 2016. Available online: https://images.apple.com/environment/p df/products/iphone/iPhone_7_PER_sept2016.pdf (accessed on 5 November 2018).

36. Woolridge, A.C.; Ward, G.D.; Phillips, P.S.; Collins, M.; Gandy, S. Life cycle assessment for reuse/recycling of donated waste textiles compared to use of virgin material: An UK energy saving perspective. Resour. Conserv. Recycl. 2006, 46, 94-103. [CrossRef]

37. Martin, E.; Shaheen, S. Greenhouse Gas Impacts of Car Sharing in North America. IEEE Trans. Intell. Transp. Syst. 2011, 12, 1074-1086. [CrossRef]

38. Martin, M.; Svensson, N.; Eklund, M. Who gets the benefits? An Approach to Assess the Environmental Performance of Industrial Symbiosis. J. Clean. Prod. 2013, 98, 263-271. [CrossRef]

39. Ekvall, T.; Weidema, B. System boundaries and input data in consequential life cycle inventory analysis. Int. J. Life Cycle Assess. 2004, 9, 161-171. [CrossRef]

40. Kjaer, L.L.; Pagoropoulos, A.; Schmidt, J.H.; McAloone, T.C. Challenges when evaluating Product/Service-Systems through Life Cycle Assessment. J. Clean. Prod. 2016, 120, 95-104. [CrossRef]

41. Brandao, M.; Martin, M.; Cowie, A.; Hamelin, L.; Zamagni, A. Consequential Life Cycle Assessment: What, How, and Why? Reference Module in Earth Systems and Environmental Sciences; Elsevier: Amsterdam, The Netherlands, 2017.

42. Barnes, S.J.; Mattsson, J. Understanding collaborative consumption: Test of a theoretical model. Technol. Forecast. Soc. Chang. 2017, 118, 281-292. [CrossRef]

43. Roos, D.; Hahn, R. Does shared consumption affect consumers' values, attitudes, and norms? A panel study. J. Bus. Res. 2017, 77, 113-123. [CrossRef]

44. Martin, M. Quantifying the Environmental Performance of an Industrial Symbiosis Network of Biofuel Producers. J. Clean. Prod. 2015, 102, 202-212. [CrossRef]

45. Laurenti, R.; Moberg, Å.; Stenmarck, Å. Calculating the pre-consumer waste footprint: A screening study of 10 selected products. Waste Manag. Res. 2017, 35, 65-78. [CrossRef] [PubMed]

46. Suckling, J.R.; Lee, J. Redefining Scope: The True Environmental Impact of Smartphones? Int. J. Life Cycle Assess. 2015, 20, 1181-1196. [CrossRef]

47. Judl, J.; Mattila, T.; Seppälä, J.; Koskela, S.; Kautto, P. Challenges in LCA comparisons of multifunctional electronic devices. In Electronics Goes Green 2012+(EGG); Institute of Electrical and Electronics Engineers (IEEE): Piscataway, NJ, USA, 2012; pp. 1-5.

48. Van Loon, P.; McKinnon, A.C.; Deketele, L.; Dewaele, J. The growth of online retailing: A review of its carbon impacts. Carbon Manag. 2014, 5, 285-292. [CrossRef] 
49. Börjesson Rivera, M.; Håkansson, C.; Svenfelt, Å.; Finnveden, G. Including second order effects in environmental assessments of ICT. Environ. Model. Softw. 2014, 56, 105-115. [CrossRef]

50. Skjelvik, J.M.; Erlandsen, A.M.; Haavardsholm, O. Environmental Impacts and Potential of the Sharing Economy; TemaNord 2017:554; Nordic Council of Ministers: Copenhagen, Denmark, 2017.

51. Benoit, S.; Baker, T.L.; Bolton, R.N.; Gruber, T.; Kandampully, J. A triadic framework for collaborative consumption (CC): Motives, activities and resources \& capabilities of actors. J. Bus. Res. 2017, 79, 219-227.

52. Pouri, M.J.; Hilty, L.M. Conceptualizing the Digital Sharing Economy in the Context of Sustainability. Sustainability 2018, 10, 4453. [CrossRef]

53. Junnila, S.; Ottelin, J.; Leinikka, L. Influence of Reduced Ownership on the Environmental Benefits of the Circular Economy. Sustainability 2018, 10, 4077. [CrossRef]

54. Pandis Iveroth, S.; Vernay, A.-L.; Mulder, K.F.; Brandt, N. Implications of systems integration at the urban level: The case of Hammarby Sjöstad, Stockholm. J. Clean. Prod. 2013, 48, 220-231. [CrossRef]

55. Billows, G.; McNeill, L. Consumer Attitude and Behavioral Intention toward Collaborative Consumption of Shared Services. Sustainability 2018, 10, 4468. [CrossRef]

(C) 2019 by the authors. Licensee MDPI, Basel, Switzerland. This article is an open access article distributed under the terms and conditions of the Creative Commons Attribution (CC BY) license (http:/ / creativecommons.org/licenses/by/4.0/). 